\author{
Е. А. Липатова, Р. М. Долинская
}

Белорусский государственный технологический университет

\title{
ФИЗИКО-МЕХАНИЧЕСКИЕ СВОЙСТВА ДВУХКОМПОНЕНТНЫХ ПОЛИУРЕТАНОВЫХ ЛАКОКРАСОЧНЫХ МАТЕРИАЛОВ
}

Полиуретановые покрытия обладают тремя главными достоинствами: высокой устойчивостью к механическому воздействию, химической стойкостью, а также (в случае применения алифатических полиизоцианатов) светостойкостью и атмосферостойкостью.

Практический диапазон применения таких покрытий распространяется как на бумагу, так и на защитные покрытия оборудования на промышленных предприятиях, поэтому исследование свойств полиуретановых композиций для защиты металлов от механических воздействий является достаточно актуальной на данный момент темой.

Целью выполнения исследовательской работы является изучение физико-механических свойств двухупаковочных лакокрасочных материалов, а именно: вязкость, прочность при растяжении.

В данной работе подобраны компоненты композиции, а также методики выполнения испытаний. Полиуретановая композиция состоит из полиэфирной смолы ПДА $800 У$ и полиизоцианата Desmodur 44V20L.

В результате проведенных исследований показано, что с увеличением времени отверждения возрастает вязкость полиуретанового покрытия, что делает его более твердым и упругим и позволяет выдерживать большие нагрузки.

Ключевые слова: полиуретановые композиции, лакокрасочные материалы, отверждение, полиэфиры, изоцианаты, пленкообразователь, отвердитель.

Для цитирования: Липатова Е. А., Долинская Р. М. Физико-механические свойства двухкомпонентных полиуретановых лакокрасочных материалов // Труды БГТУ. Сер. 2, Химические технологии, биотехнологии, геоэкология. 2021. № 1 (241). С. 182-185.

\section{E. A. Lipatova, R. M. Dolinskaya \\ Belarusian State Technological University \\ PHYSICAL AND MECHANICAL PROPERTIES OF TWO-COMPONENT POLYURETHANE PAINT MATERIALS}

Polyurethane coatings have three main advantages: high resistance to mechanical stress, chemical resistance, and (in the case of aliphatic polyisocyanates) light resistance and weather resistance.

The practical range of application of such coatings extends both for paper and for protective coatings of equipment in industrial enterprises, so the study of the properties of polyurethane compositions for protecting metals from mechanical influences is quite relevant at the moment.

The purpose of the research work is to study the physical and mechanical properties of two-pack paint and varnish materials, namely: viscosity, tensile strength.

In this paper, the components of the composition are selected, as well as the methods of performing tests. Polyurethane composition consists of PDA 800U polyester resin and Desmodur 44V20L polyisocyanate.

As a result of the conducted research, it is shown that with increasing curing time, the viscosity of the polyurethane coating increases, which makes it harder and more elastic and allows it to withstand heavy loads.

Key words: polyurethane compositions, paint and varnish materials, curing, polyesters, isocyanates, film-forming agent, hardener.

For citation: Lipatova E. A., Dolinskaya R. M. Physical and mechanical properties of twocomponent polyurethane paint materials. Proceedings of BSTU, issue 2, Chemical Engineering, Biotechnologies, Geoecology, 2021, no. 1 (241), pp. 182-185 (In Russian).

Введение. В настоящее время на мировом рынке имеется довольно широкий выбор сырьевых компонентов для двухупаковочных полиуретановых и эпоксидных лакокрасочных материалов (ЛКМ). Двухупаковочные полиурета- новые ЛКМ хорошо известны благодаря уникальному сочетанию твердости и эластичности образующихся покрытий. Наряду с уникальными эксплуатационными свойствами полиуретаны имеют еще одно неоспоримое досто- 
инство: на их основе несложно изготовить экологически чистые ЛКМ, полностью удовлетворяющие современным санитарным требованиям.

В настоящее время такие лакокрасочные материалы широко используются для покрытий металлических изделий для защиты от различных повреждений благодаря своей прочности и эластичности.

Основная часть. Наиболее известными двухупаковочными лакокрасочными материалами являются полиуретановые композиции. Один из компонентов этих композиций - пленкообразователь, а иногда его смеси с пигментами, и это является основой (компонент А), второй компонент - отвердитель (компонент В). Bce пленки, изготовленные на основе полиуретановых красок, имеют полимерную структуру со связями через уретановые, карбамидные, биуретовые или аллофанатные группы. Связи могут возникать во время отверждения краски в результате реакции полиаддитивности исходных продуктов, обладающих относительно небольшой молекулярной массой. Кроме того, краски могут содержать полимеры, обладающие большой молекулярной массой, заранее синтезированные соединения соответствующих мономеров. Часто встречаются высокомолекулярные аддукты с избытком изоцианатных групп или аддукты, в которых отверждение происходит через окисление сопряженных двойных связей.

Сырьем для полиуретановых ЛКМ служат изоцианаты и гидроксильные пленкообразователи [1].

Свойства полиуретановых покрытий зависят от равномерности и плотности образующихся мостиковых связей, определяющих их химическую стойкость, твердость и механическую прочность покрытия, а также от числа образованных уретановыми группами водородных мостиков, которые придают покрытию эластичность.

В традиционных двухкомпонентных системах полиуретановых красок высокомолекулярные соединения, содержащие гидроксильные группы, образуют «основу», которая структурируется в результате отверждения с полиизоцианатами [2].

Цель данной работы - изучение свойств лакокрасочных полиуретановых двухкомпонентных композиций, синтезированных из полиэфирной смолы ПДА $800 У$ и полиизоцианата Desmodur 44V20L.

Смола представляет собой продукт поликонденсации диэтиленгликоля с адипиновой кислотой светло-желтого цвета.

Изоцианат Desmodur 44V20L - жидкий коричневый продукт, представляющий собой смесь 4,4' -дифенилметандиизоцианата (МДИ) с изомерами и гомологами более высокой функциональности.

Вязкость образцов измеряли на ротационном вискозиметре серии ADVANCE.

Измерение вязкости проводили в соответствии с ГОСТ 25276-82. Регулирование и калибровку вискозиметра проводили в соответствии с инструкцией, прилагаемой к прибору, применяя жидкость известной вязкости.

Значение скорости сдвига, при которой измерялась вязкость, составляла 12 об/мин.

Синтезированную лакокрасочную композицию помещали в прибор для термостатирования. Температура и продолжительность термостатирования $-20^{\circ} \mathrm{C}$ в течение 30 мин.

После термостатирования проводили испытания. Промежуток времени, по истечении которого начинали испытания, составлял 1 мин.

Испытания проводили для двух проб, по 3 раза для каждой пробы. Результат испытания среднее арифметическое значение определений.

Синтезированы полимерные композиции с различными соотношениями пленкообразователь : отвердитель (табл. 1).

Таблица 1

Рецептура двухкомпонентной композиции

\begin{tabular}{|c|c|c|c|}
\hline \multirow{2}{*}{$\begin{array}{c}\text { Компоненты } \\
\text { композиции }\end{array}$} & \multicolumn{3}{|c|}{ Образцы } \\
\cline { 2 - 4 } & 1 & 2 & 3 \\
\hline Полиэфирная смола, г & 200 & 200 & 200 \\
\hline Полиизоцианат, г & 65,8 & 72,38 & 59,22 \\
\hline Соотношение пленкообразователь : отвердитель \\
\hline \multicolumn{5}{|c}{$3: 1$} & $2,76: 1$ & $3,38: 1$ \\
\hline
\end{tabular}

На рис. 1 приведена зависимость вязкости от времени отверждения.

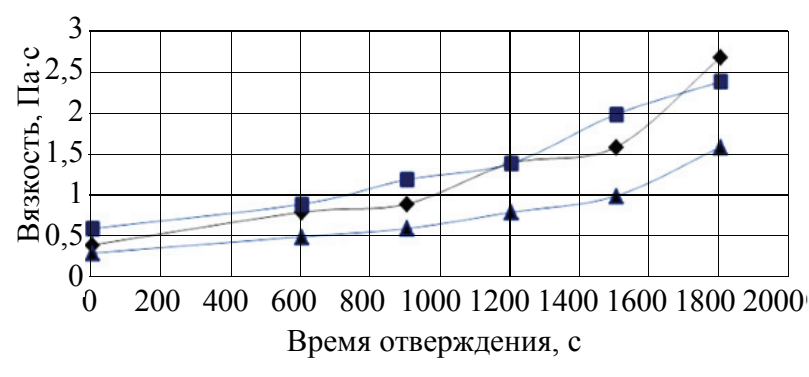

•- Избыток отвердителя - Недостаток отвердителя

^ Оптимальное количество

Рис. 1. Зависимость вязкости от времени отверждения

Как видим, вязкость увеличивается равномерно с увеличением времени отверждения (рис. 1), что свидетельствует о сшивке изоцианатных с гидроксильными группами. Такой 
эффект установили и в работе [3] при смешении компонентов защитного покрытия.

Как видно (рис. 1), при соблюдении температурного режима (образцы необходимо смешивать при температуре $20^{\circ} \mathrm{C}$ ) вязкость изменяется плавно, так как сшивка полиизоцианата и полиэфира происходит постепенно.

Затем в сушильном шкафу проводили полимеризацию образцов при температуре $60^{\circ} \mathrm{C}$ в течение 48 ч.

Прочность при растяжении полимеризованных образцов испытывали при температурах +20 и $-50^{\circ} \mathrm{C}$ (для того чтобы образец гарантированно перешел из высокоэластичного в стеклообразное состояние).

Результаты испытаний на прочность при растяжении при температуре $-50^{\circ} \mathrm{C}$ приведены в табл. 2.

Таблица 2

Физико-механические показатели образцов при избытке отвердителя

\begin{tabular}{|l|c|c|c|}
\hline \multicolumn{1}{|c|}{ Параметр } & \multicolumn{3}{c|}{ Образцы } \\
\cline { 2 - 4 } & 1 & 2 & 3 \\
\hline Удлинение, мм & 13 & 16 & 14 \\
\hline Улинение, \% & 26 & 32 & 28 \\
\hline $\begin{array}{l}\text { Максимальная нагруз- } \\
\text { ка, Н }\end{array}$ & 3970,15 & 3668,06 & 3515,42 \\
\hline
\end{tabular}

Как видно (табл. 2), образцы в стеклообразном состоянии выдерживают достаточно большую нагрузку, практически не удлиняясь, что свидетельствует об образовании оптимального количество уретановых групп.

Результаты испытаний образцов на прочность при растяжении при недостатке отвердителя при температуре $-50^{\circ} \mathrm{C}$ приведены на рис. 2 .

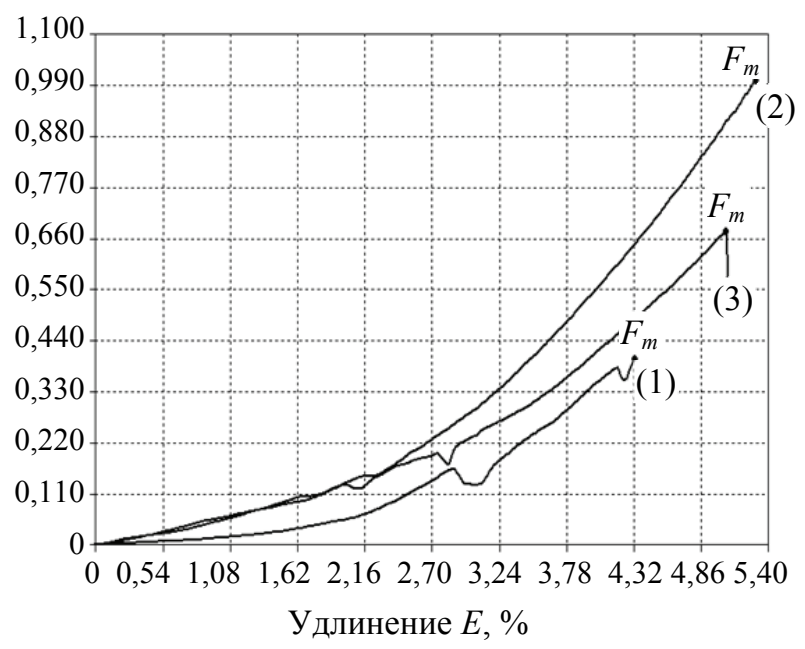

Рис. 2. Зависимость нагрузки от удлинения

Как видно (рис. 2), при недостатке полиизоцианата образцы характеризуются повы- шенными показателями удлинения, что свидетельствует о неполной сшивке изоцианатных с гидроксильными группами.

Результаты испытаний на прочность при оптимальном содержании отвердителя (температура $\left.-50^{\circ} \mathrm{C}\right)$ приведены в табл. 3 .

Данная композиция достаточно эластичная и выдерживает большие нагрузки при растяжении.

Образец № 1 не выдержал приложенной нагрузки, так как имел видимый дефект, полученный при синтезе.

Таблица 3

Физико-механические показатели образцов при оптимальном количестве отвердителя

\begin{tabular}{|l|c|c|c|}
\hline \multicolumn{1}{|c|}{ Параметр } & \multicolumn{3}{|c|}{ Образцы } \\
\cline { 2 - 4 } & 1 & 2 & 3 \\
\hline Удлинение, мм & 7 & 12 & 16 \\
\hline Удлинение, \% & 14 & 24 & 32 \\
\hline $\begin{array}{l}\text { Максимальная нагруз- } \\
\text { ка, Н }\end{array}$ & 1571,07 & 4512,03 & 4852,21 \\
\hline
\end{tabular}

Результаты испытаний на прочность при недостатке отвердителя при температуре $20^{\circ} \mathrm{C}$ приведены в табл. 4.

Как видим из данных, представленных в табл. 4, образцы композиции обладают достаточной эластичностью при растяжении, при этом они не выдерживают требуемых нагрузок.

Таблица 4

Физико-механические показатели образцов при недостатке отвердителя

\begin{tabular}{|l|c|c|c|}
\hline \multicolumn{1}{|c|}{ Параметр } & \multicolumn{3}{|c|}{ Образцы } \\
\cline { 2 - 4 } & 1 & 2 & 3 \\
\hline Удлинение, мм & 34 & 34 & 33 \\
\hline Удлинение, \% & 68 & 68 & 66 \\
\hline $\begin{array}{l}\text { Максимальная нагруз- } \\
\text { ка, Н }\end{array}$ & 16,51 & 11,92 & 22,9 \\
\hline
\end{tabular}

Визуальный анализ образцов показал наличие дефектов в виде пузырьков воздуха, вероятно, в процессе синтеза были заблокированы некоторые участки молекул, что не позволило полностью удалить воздух и, возможно, даже влагу, поэтому при растяжении образцы обладали минимальными значениями деформации.

Следовательно, из-за недостатка отвердителя образцы максимально эластичны и не выдерживают нагрузки выше 22,9 Н, что свидетельствует о недостаточном количестве уретановых групп, которые образовались при смешении полиэфирной смолы и полиизоцианата.

Результаты испытаний на прочность при оптимальном содержании отвердителя при температуре $20^{\circ} \mathrm{C}$ приведены в табл. 5 . 
Анализ полученных результатов показал, что при оптимальном количестве отвердителя нагрузка растет пропорционально удлинению.

При испытании на прочность при растяжении в высокоэластичном состоянии образцы испытывают достаточно большое удлинение (56-68\%), в то время как в стеклообразном состоянии этот показатель составил 8-32\%.

Таблица 5

Физико-механические показатели образцов при оптимальном количестве отвердителя

\begin{tabular}{|l|c|c|c|}
\hline \multirow{2}{*}{\multicolumn{1}{|c|}{ Параметр }} & \multicolumn{3}{c|}{ Образцы } \\
\cline { 2 - 4 } & 1 & 2 & 3 \\
\hline Удлинение, мм & 28 & 29 & 27 \\
\hline Удлинение, \% & 56 & 58 & 54 \\
\hline Максимальная нагрузка, $\mathrm{H}$ & 60,03 & 67,37 & 46,58 \\
\hline
\end{tabular}

Таким образом, как в высокоэластичном, так и в стеклообразном состояниях образцы, содержащие оптимальное количество отвердителя, выдерживают большие нагрузки при рас- тяжении, что свидетельствует о том, что процесс полимеризации прошел до конца и образовалось требуемое количество полиуретановых групп и, соответственно, достигнута высокая прочность полиуретановой композиции.

Пики, которые образуются при минимальном удлинении, соответствуют деформациям внутри образца из-за наличия дефектов в виде мелких пузырьков воздуха.

Такие композиции и защитные покрытия на их основе могут использоваться при повышенных (до 70-90 ${ }^{\circ}$ ) температурах [4].

Заключение. Разработанные двухкомпонентные полиуретановые композиции для изготовления защитных лакокрасочных покрытий обладают высоким комплексом физико-механических свойств (максимальная нагрузка 46,58-67,37 H, удлинение 54-58\%). Установлено, что с увеличением времени отверждения до 2000 с вязкость возрастает до 3 Па · с полиуретанового покрытия, что делает его более твердым и упругим и позволяет выдерживать большие нагрузки.

\section{Список литературы}

1. Мюллер Б., Пот У. Лакокрасочные материалы и покрытия. Принципы составления рецептур. М.: Пэйнт-Медиа, 2007. 72 с.

2. Д. Стойе, В. Фрейстаг. Краски, покрытия и растворители, СПб.: Профессия, 2007. 92 с.

3. Покрытие из дендритного полиуретана: пат. 2156407 Рос. Федерация, № 2011102479/05; заявл. 08.07.2009; опубл. 20.05.2014. Бюл. № 14. 29 с.

4. Наружное полиуретановое двухкомпонентное защитное покрытие (варианты): пат. 2481367 , Рос. Федерация, № 2012126174/05; заявл. 25.06.2012; опубл. 10.05.2013. Бюл. № 13. 10 с.

\section{References}

1. Muller B., Pot U. Lackformulierung und Lackrezeptur: Das Lehrbuch für Ausbildung und Praxis. Hannover, Vincentz Network GmbH \& C, 2006. 72 p. (Russ. ed.: Muller B., Pot U. Lakokrasochnye materialy i pokrytiya. Principy sostavleniya receptur. Moscow, Paint-Media, 2007. 72 p).

2. D. Stoye, W. Freitag. Paints, coatings and solvents. Weinheim, Wiley-VCH. 1998. 431 p. (Russ. ed.: D. Stoye, W. Freitag. Kraski, pokrytiya i rastvoriteli. SPb.: Profession, 2007. 431 p.).

3. Choate Thomas F. Pokrytie iz dendritnogo poliuretana [The coating of the dendritic polyurethane] Patent RF, no. 2156407, 2014.

4. Valiulin E. D, Razgulyaev S. V. Naruzhnoe poliuretanovoe dvuhkomponentnoe zashchitnoe pokrytie (varianty) [External polyurethane two-component protective coating (versions)]. Patent RF, no. 2481367, 2013.

\section{Информация об авторах}

Липатова Елизавета Андреевна - студентка. Белорусский государственный технологический университет (220006, г. Минск, ул. Свердлова, 13a, Республика Беларусь). E-mail: lipatova.200312@gmail.com

Долинская Раиса Моисеевна - кандидат химических наук, доцент, доцент кафедры полимерных композиционных материалов. Белорусский государственный технологический университет (220006, г. Минск, ул. Свердлова, 13a, Республика Беларусь). E-mail: raisa_dolinskaya@mail.ru

\section{Information about the authors}

Lipatova Elizaveta Andreevna - student. Belarusian State Technological University (13a, Sverdlova str., Minsk, 220006, Republic of Belarus). E-mail: lipatova.200312@gmail.com

Dolinskaya Raisa Moiseevna - PhD (Chemistry), Associate Professor, Assistant Professor, the Department of Polymer Composite Materials. Belarusian State Technological University (13a, Sverdlova str., 220006, Minsk, Republic of Belarus). E-mail: raisa_dolinskaya@mail.ru 